\title{
Adult medulloblastoma mimicking Lhermitte-Duclos disease: Can diffusion weighted imaging help?
}

Puneet M ittal, Kamini Gupta, Kavita Saggar, Supreet Kaur

Department of Radiodiagnosis, Dayanand Medical College and Hospital, Ludhiana, Punjab, India

Address for correspondence: Dr. Puneet M ittal,

Department of Radiodiagnosis,

Dayanand Medical College \&

Hospital, Tagore Nagar, Civil Lines,

Ludhiana, Punjab - 141 001, India.

E-mail: drpuneetmittal@gmail.com

DOI: $10.4103 / 0028-3886.51297$

\begin{abstract}
Abstrat
Lhermitte-Duclos disease, also known as dysplastic cerebellar gangliocytoma, is a rare cerebellar benign tumor with characteristic appearance of thickened cerebellar folia giving a laminated or striated appearance, euite diagnostic of the condition. We had seen a patient with medulloblastoma with imaging findings suspicious for thickened cerebellar folia reminiscent of Lhermitte-Duclos disease. However, it showed patchy contrast enhancement and restricted diffusion on diffusion-weighted imaging, which are not typically associated with Lhermitte-Duclos disease. Presence of restricted diffusion proved to be a useful diagnostic feature for differentiation between the two lesions. This patient highlights the importance of obtaining all the MR imaging sequences in suspected Lhermitte-Duclos disease and histological diagnosis if there is doubt.
\end{abstract}

Key words: Diffusion, folia, gang liocytoma, Lhermitte-Duclos, medulloblastoma

\section{Introduction}

Medulloblastoma accounts for $\sim 1 \%$ of adult brain tumors and $14-35 \%$ of medulloblastomas occurs in adults and show atypical features. ${ }^{[1-3]}$ Lhermitte-Duclos disease is a rare entity and about 220 cases have been reported till 2006. ${ }^{[4]}$ We present an adult patient with medulloblastoma with suspicion of abnormal folia thickening masquerading as Lhermitte-Duclos disease. Our review of literature showed only two such case reports of medulloblastoma in children ${ }^{[5,6]}$ Both of them were misdiagnosed as Lhermitte-Duclos disease.

\section{Case Report}

A 19-year-old male patient presented with headache, projectile vomiting, and weight loss of two months duration. Two days prior to the contrast magnetic resonance imaging (MRI) study, a ventriculoperitoneal (VP) shunt was placed for obstructive hydrocephalus. The contrast MRI revealed an ill-defined right cerebellar mass with suspicion of thickened cerebellar folia giving a striated appearance involving the vermis and middle cerebellar peduncle causing mass effect on the brainstem and fourth ventricle and transtentorial herniation. The lesion was hypointense on T1-weighted (T1W) images [Figure 1a], and iso to mildly hyperintense on T2-weighted (T2W) [Figure 1b] and fluid attenuation and inversion recovery (FLAIR) images [Figure 1c]. On postcontrast images, mild patchy enhancement was seen [Figure 1d]. The mass showed restricted diffusion on diffusion weighted (DW)/apparent diffusion coefficient (ADC) images [Figures 2a-b]. Calculated ADC value in the region of the mass was $303 \mu \mathrm{m}^{2} / \mathrm{s}$ while the ADC value in the adjacent normal cerebellar white matter was $707 \mu \mathrm{m}^{2} / \mathrm{s}$. Appearance of thickened folia in this patient suggested the diagnostic possiblity of LhermitteDuclos disease. However, contrast enhancement and restricted diffusion were atypical features. Possibilities of Lhermitte-Duclos disease and medulloblastoma were considered. On surgical pathology, it was proven to be medulloblastoma.

\section{Discussion}

Medulloblastoma is a malignant primitive neuroectodermal tumor. Although it is generally considered to be a childhood tumor, a significant number of cases (14-35\%) 

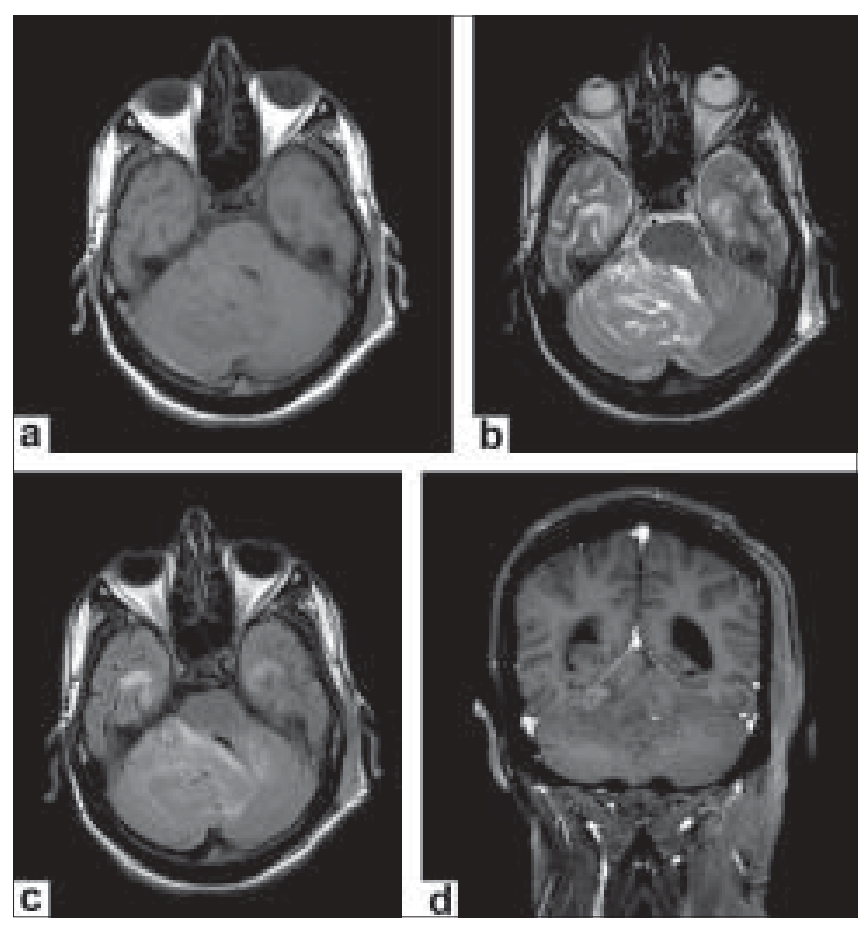

Figure 1 : (a) Axial T1 weighted MR section at the level of pons showing ill-marginated iso to hypointense mass lesion with laminated appearance in the right cerebellum and vermis; (b) Axial T2 weighted image at the same level showing diffuse nodular enlargement of cerebellar folia with laminated appearance showing iso to mildly hyperintense signal; (c) Axial FLAIR image showing iso to mildy hyperintense signal with laminated appearance; (d) Coronal postcontrast T1 weighted image showing patchy enhancement in the lesion

occur in adults with maximum incidence between 15 and 19 years of age. ${ }^{[1-3]}$ Medulloblastoma is thought to arise from primitive neuroectodermal cells found in the floor of the fourth ventricle. These cells migrate upward and laterally to form the external granular layer. Medulloblastoma can develop anywhere along this path. Furthermore, the cells migrate more laterally with increasing age, this may explain the midline location of these tumors in children and the lateral location in adults. ${ }^{[7,8]}$ The cerebellar location of medulloblastoma is between $50 \%$ and $63 \%$. ${ }^{[7,9]}$

The classical imaging appearance of medulloblastoma is that of a homogeneous midline vermian mass which shows uniform enhancement without any necrosis or cystic areas. While these features are seen more commonly in children, in adult tumor tends to be more heterogenous with cystic and necrotic areas. Tumor tends to be isointense on $\mathrm{T} 2 \mathrm{~W}$ images. This feature is attributed to hypercellularity of the tumor and also desmoplastic medulloblastomas.being more common in adults. In adults contrast enhancement is variable ${ }^{[8,10]}$ Medulloblastomas, like all other primitive neuroectodermal tumors, are hypercellular tumors. These are associated with less amount of extracellular water. This histological pattern is responsible for the restricted diffusion seen in medulloblastoma and could be potentially useful in differentiating it from other tumors. ${ }^{[10,11]}$

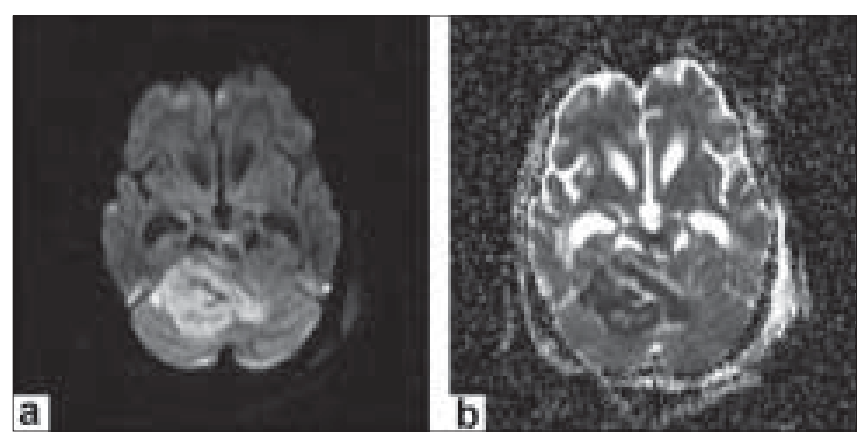

Figure 2: (a) Axial diffusion weighted image showing hyperintense signal within the mass; (b) Corresponding apparent diffusion coefficient map showing hypointense signal confirming the presence of diffusion restriction

Lhermitte-Duclos disease, also known as dysplastic cerebellar gangliocytoma, is an uncommon tumor of uncertain origin, commonly seen in adults. It is classified as World Health Organization (WHO) grade I tumor. ${ }^{[12]}$ MRI is the imaging modality of choice. Typically the cerebellar hemispheric mass does not enhance on contrast and is hypointense on T1W and hyperintense on T2W images with characteristic laminated appearance due to abnormal thickening of cerebellar folia. It is usually unilateral but can extend into the vermis. ${ }^{[13,14]}$ Although it is usually an avascular lesion, few cases with contrast enhancement have been reported ${ }^{[15,16]}$ On diffusion-weighted imaging, Lhermitte-Duclos disease shows increased signal intensity due to T2 shine-through effect rather than restricted diffusion as reflected by lack of hypointensity on ADC mapping. ${ }^{[13,17,18]}$

In our case, the findings closely resembled that of Lhermitte-Duclos disease with thickened folia. Mild contrast enhancement has also been reported in Lhermitte-Duclos disease. Presence of restricted diffusion in our case led us to suspect the diagnosis of medulloblastoma. In the two previous such cases the initial diagnosis was Lhermitte-Duclos disease. The patient reported by Someshwar et al. ${ }^{[3]}$ had restricted diffusion, however this finding was not considered in the diagnosis.

MR spectroscopy can be useful in the differential diagnosis. Medulloblastoma shows typical characteristics of a mitotic lesion with increased choline (Cho)/ creatine $(\mathrm{Cr})$ and $\mathrm{Cho} / \mathrm{N}$-Acetyl Aspartate (NAA) ratios. ${ }^{[19]}$ On the other hand, Lhermitte-Duclos disease shows spectroscopic findings of a hamartomatous lesion., decreased NAA/Cr ratios and no increase in Cho/ $\mathrm{Cr}$ ratio. ${ }^{[17,20]}$ Both medulloblastoma and Lhermitte-Duclos disease can show increased perfusion parameters on MR perfusion imaging. ${ }^{[2,21]}$

This case highlights the importance of doing all the MRI sequences in suspected cases of Lhermitte-Duclos 
disease. Presence of restricted diffusion might question the diagnosis of Lhermitte-Duclos disease. Such cases should be considered for early histological diagnosis, as management of Lhermitte-Duclos disease and medulloblastoma is different and misdiagnosis can be potentially harmful.

\section{References}

1. Giordana MT, Schiffer P, Lanotte M, Girardi P, Chio A. Epidemiology of adult medulloblastoma. Int J Cancer 1999;80:689-92.

2. Eisenstat DD. Clinical management of medulloblastoma in adults. Expert Rev Anticancer Ther 2004;4:795-802.

3. Becker RL, Becker AD, Sobel DF. Adult medulloblastoma: Review of 13 cases with emphasis on MRI. Neuroradiology 1995;37:104-8.

4. Robinson S, Cohen AR. Cowden disease and Lhermitte-Duclos disease: An update. Case report and review of the literature. Neurosurg Focus 2006;20:E6.

5. Chen KS, Hung PC, Wang HS, Jung SM, Ng SH. Medulloblastoma or cerebellar dysplastic gangliocytoma (Lhermitte-Duclos disease)? Pediatr Neurol 2002;27:404-6.

6. Someshwar S, Hogg JP, Nield LS. Lhermitte-Duclos Disease or Neoplasm? Consultantlive.com 2007;3. Available from: http://www.consultantlive.com/ display/article/10168/57026. [last assessed 2008 Sep 13].

7. Bourgouin PM, Tampieri D, Grahovac SZ, Léger C, Del Carpio R, Melançon D. CT and MR imaging findings in adults with cerebellar medulloblastoma: Comparison with findings in children. AJR Am J Roentgenol 1992;159:609-12.

8. Koeller KK, Rushing EJ. From the archives of the AFIP: medulloblastoma: A comprehensive review with radiologic-pathologic correlation. Radiographies 2003;23:1613-37.

9. de Carvalho Neto A, Gasparetto EL, Ono SE, Bertoldi GA, Gomes AF. Adult cerebellar medulloblastoma: CT and MRI findings in eight cases. Arq Neuropsiquiatr 2003;61:199-203.

10. Rodallec M, Colombat M, Krainik A, Kalamaridès M, Redondo A, Feydy A. Diffusion-weighted MR imaging and pathologic findings in adult cerebellar medulloblastoma. J Neuroradiol 2004;31:234-7.

11. Provenzale JM, Mukundan S, Barboriak DP. Diffusion-weighted and perfusion MR imaging for brain tumor characterization and assessment of treatment response. Radiology $2006 ; 239: 632-49$.

12. Louis DN, Ohgaki H, Wiestler OD, Cavenee WK, Burger PC, Jouvet A, et al. The $2007 \mathrm{WHO}$ classification of tumours of the central nervous system. Acta Neuropathol 2007;114:97-109.

13. Wu CH, Chai JW, Lee CH, Chen WH, Lee T, Chen CC. Assessment with magnetic resonance imaging and spectroscopy in Lhermitte-Duclos disease. J Chin Med Assoc 2006;69:338-42.

14. Shin JH, Lee HK, Khang SK, Kim DW, Jeong AK, Ahn KJ, et al. Neuronal tumors of the central nervous system: Radiologic findings and pathologic correlation. Radiographics 2002;22:1177-89.

15. Spaargaren L, Cras P, Bomhof MA, Lie ST, de Barsy AM, Croese PH, et al. Contrast enhancement in Lhermitte-Duclos disease of the cerebellum: Correlation of imaging with neuropathology in two cases. Neuroradiology 2003;45:381-5.

16. Awwad EE, Levy E, Martin DS, Merenda GO. Atypical MR appearance of Lhermitte-Duclos disease with contrast enhancement. AJNR Am $J$ Neuroradiol 1995;16:1719-20.

17. Klisch J, Juengling F, Spreer J, Koch D, Thiel T, Büchert M, et al. Lhermitte-Duclos disease: Assessment with MR imaging, positron emission tomography, single-photon emission CT, and MR spectroscopy. AJNR Am J Neuroradiol 2001;22:824-30.

18. Thomas B, Krishnamoorthy T, Radhakrishnan VV, Kesavadas C. Advanced MR imaging in Lhermitte-Duclos disease: Moving closer to pathology and pathophysiology. Neuroradiology 2007;49:733-8.

19. Majós C, Alonso J, Aguilera C, Serrallonga M, Acebes JJ, Arús C, et al. Adult primitive neuroectodermal tumor: Proton MR spectroscopic findings with possible application for differential diagnosis. Radiology 2002;225:556-66.

20. Haris AA, Chandra SR, Peethambaran B. Lhermitte-Duclos disease. Neurol India 2008;56:495-6.

21. Law M, Kazmi K, Wetzel S, Wang E, Iacob C, Zagzag D, et al. Dynamic Susceptibility Contrast-Enhanced Perfusion and Conventional MR Imaging Findings for Adult Patients with Cerebral Primitive Neuroectodermal Tumors. AJNR Am J Neuroradiol 2004;25: 997-1005.

Accepted on 31-03-2009

Source of Support: Nil, Conflict of Interest: None declared. 